\title{
Marinated Sea Bream Fillets Enriched with Lactiplantibacillus plantarum and Bifidobacterium animalis subsp. lactis: Brine Optimization and Product Design
}

\author{
Barbara Speranza, Antonio Bevilacqua (D, Angela Racioppo, Daniela Campaniello, Milena Sinigaglia \\ and Maria Rosaria Corbo *(D)
}

Citation: Speranza, B.; Bevilacqua, A.; Racioppo, A.; Campaniello, D.; Sinigaglia, M.; Corbo, M.R. Marinated Sea Bream Fillets Enriched with Lactiplantibacillus plantarum and Bifidobacterium animalis subsp. lactis: Brine Optimization and Product Design. Foods 2021, 10, 661

https://doi.org/10.3390/foods10030661

Academic Editors: Pasquale Filannino and Montserrat Dueñas Patón

Received: 24 January 2021

Accepted: 15 March 2021

Published: 19 March 2021

Publisher's Note: MDPI stays neutral with regard to jurisdictional claims in published maps and institutional affiliations.

Copyright: (c) 2021 by the authors. Licensee MDPI, Basel, Switzerland. This article is an open access article distributed under the terms and conditions of the Creative Commons Attribution (CC BY) license (https:// creativecommons.org/licenses/by/ $4.0 /)$
Department of Agriculture, Food, Natural Resources and Engineering, University of Foggia, 71122 Foggia, Italy barbara.speranza@unifg.it (B.S.); antonio.bevilacqua@unifg.it (A.B.); angela.racioppo@unifg.it (A.R.); daniela.campaniello@unifg.it (D.C.); milena.sinigaglia@unifg.it (M.S.)

* Correspondence: mariarosaria.corbo@unifg.it; Tel.: +39-0881-589232

\begin{abstract}
This study aimed to design marinated sea bream fillets, inoculated with either Lactiplantibacillus plantarum (strains 11, 68, 69) or Bifidobacterium animalis subsp. lactis DSM 10140. In the first step, the optimization of brine composition was performed through a centroid; the factors of the design were citric acid, vinegar, and salt. As a result of optimization, the optimal composition of brine was set to $0.75 \%$ citric acid, $55 \%$ vinegar, and $3 \% \mathrm{NaCl}$. In the second step, sea bream fillets were inoculated with L. plantarum strain 69 and B. animalis subsp. lactis, marinated and then packed in a conditioning solution (oil or diluted brine); the samples were stored at $4{ }^{\circ} \mathrm{C}$ for 21 days. The viability of the strains and sensory scores were assessed. The bacteria retained a high viability throughout storage (21 days); however, the sensory scores were at their highest level for 4 days. In particular, sensory assessment suggested a preference for a conditioning solution with oil, rather than with a diluted brine. In addition, a slightly higher preference was found for B. animalis subsp. lactis.
\end{abstract}

Keywords: brine; marination; functional strains; optimization; sea bream

\section{Introduction}

The awareness that probiotic foods can have beneficial effects on health has led to an increase of consumer requests for these products. In order for probiotic bacteria to have a beneficial effect on human health, they must survive and remain viable during the expected shelf life of the probiotic food or beverage, without producing negative effects on the sensory properties of the food itself [1].

Results from numerous investigations indicate that probiotics supplied with food are more easily adaptable to the conditions in the gastrointestinal tract and are more effective in maintaining good gut health than probiotics embedded in pharmaceutical preparations [2].

Functional and probiotic foods are mostly enclosed in dairy foods (yogurt, kefir, acidophilus milk, etc.). However, the increase in lactose intolerance and allergies to milk proteins are the leading factors for non-dairy probiotic foods, such as probiotic fermented cereals, fruits, vegetables, and fruit juices [3-6]. Some studies have focused attention on fermented probiotic seasoned dried sausages [7], fermented soy milk, oat-based cereal bars, olives, and artichokes [8].

Although this trend has affected several segments of the agri-food industry, the fish products sector has not yet been significantly affected by this new generation of food products.

It is well known that fish is widely perceived by consumers as healthy food, because it is a source of polyunsaturated fatty acids, essential minerals and vitamins, and has a high protein content $[9,10]$. In particular, fish is rich in omega-3 polyunsaturated fatty acids (PUFAs), including docosahexaenoic acid (DHA) and eicosapentaenoic acid (EPA), both well 
known to prevent cardiovascular diseases [11,12]. In addition, some researchers showed a positive effect on metabolic syndrome and prevention of cardiovascular disease [13,14], as well as on life expectancy and reduction of the incidence of obesity [15].

Some authors proposed the addition of probiotic strains in fermented fish [16,17] and in marinated fish products. In 2012, Speranza et al. [18] proposed an innovative probiotic food-that is, marinated anchovies enriched with L. plantarum c19. In another study, marinated swordfish fillets were inoculated with Lacticaseibacillus paracasei IMPC 2.1 [19]. The results showed that inoculation successfully ensured the growth of the probiotic strain and controlled the growth of other lactic acid bacteria (LAB).

This technique appears to be an effective means of maintaining the microbial quality of fish fillets and an alternative tool for delivering probiotics. Therefore, the aim of this research was to develop probiotic marinated sea bream fillets. The study was divided into two different steps: 1 . brine optimization to ensure the survival of probiotic microorganisms; 2 . functional fish product optimization packaged in different solutions.

\section{Materials and Methods}

\subsection{Microorganisms}

Three autochthonous strains of Lactiplantibacillus plantarum (previously known as Lactobacillus plantarum [20]), namely, strains 11, 68, and 69 isolated from intestinal microbiota of sea bream and with functional properties [21], and Bifidobacterium animalis subsp. lactis DSM 10140 (Deutsche Sammlung von Mikroorganismen und Zellkulturen) were used throughout this research. The microorganisms were stored at $-20^{\circ} \mathrm{C}$ in MRS broth (Oxoid, Milan, Italy) added with $33 \%$ of sterile glycerol and grown under anaerobic conditions in MRS broth $\left(37^{\circ} \mathrm{C}\right.$ for $\left.24 \mathrm{~h}\right)$.

\subsection{Brine Optimization}

\subsubsection{Brine Optimization: Experimental Design}

Brine optimization was obtained using a simplex centroid. In this research, three independent variables were chosen: vinegar, $\mathrm{NaCl}$, and citric acid, and were included in the range $40-70 \%, 0-12 \%$, and $0-1.5 \%$, respectively. Each variable was set at 4 different levels, identified with the codes 0 (minimum), 1 (maximum), 0.5 (half point of the interval), and 0.33 (1/3 of the maximum). Table 1 reports the 7 combinations of the centroid and the control (i.e., a further combination where the vinegar, $\mathrm{NaCl}$, and citric acid were set to $0.0 \%$, simulating the optimal conditions). In particular, four centroids were performed for each target strain.

Table 1. Combinations of centroid.

\begin{tabular}{|c|c|c|c|c|c|c|}
\hline & \multicolumn{3}{|c|}{ Coded Values } & \multicolumn{3}{|c|}{ Real Values } \\
\hline & Vinegar & $\mathrm{NaCl}$ & Citric Acid & Vinegar (\%) & $\mathrm{NaCl}(\%)$ & Citric Acid (\%) \\
\hline 1 & 1 & 0 & 0 & 70 & 0 & 0 \\
\hline 2 & 0 & 1 & 0 & 40 & 12 & 0 \\
\hline 3 & 0 & 0 & 1 & 40 & 0 & 1.50 \\
\hline 4 & 0.50 & 0.50 & 0 & 55 & 6 & 0 \\
\hline 5 & 0.50 & 0 & 0.50 & 55 & 0 & 0.75 \\
\hline 6 & 0 & 0.50 & 0.50 & 40 & 6 & 0.75 \\
\hline 7 & 0.33 & 0.33 & 0.33 & 50 & 4 & 0.50 \\
\hline Control & - & - & - & - & - & - \\
\hline
\end{tabular}

\subsubsection{Sampling}

Agar diskettes $(2 \% w / v)$ were used to simulate a fish fillets model system. Before use, the four probiotic strains were grown in MRS broth (Oxoid) and incubated at $37^{\circ} \mathrm{C}$ for $24 \mathrm{~h}$. The microorganisms were centrifuged at $4000 \times g$ for $10 \mathrm{~min}$, the supernatant was discarded, and the pellet was suspended in sterile saline solution $(0.9 \% \mathrm{NaCl})$. This 
cell suspension ( $9 \log \mathrm{CFU} / \mathrm{mL}$ ) was used to inoculate a test tube containing a sterile and liquid agar solution $\left(2 \%, 55^{\circ} \mathrm{C}\right)$ at $8 \log \mathrm{CFU} / \mathrm{mL}$. Immediately after inoculation, the agar solution was put in Petri dishes and left to dry for $1 \mathrm{~h}$; then brine solutions were added on the surface of each plate (ratio agar/solution, 1:1.5), and the viable count of probiotics was evaluated after 24 and $48 \mathrm{~h}$. Agar pieces $(20 \mathrm{~g})$ were taken and diluted in $180 \mathrm{~mL}$ of saline solution in a Stomacher bag (Seward, London, England), then homogenized for $1 \mathrm{~min}$ in a Seward Stomacher Lab Blender 400. Serial dilutions of the homogenates were inoculated on MRS agar and incubated at $37^{\circ} \mathrm{C}$ for $24-48 \mathrm{~h}$ under anaerobic conditions. All tests were performed in duplicate over two different batches.

All microbiological data were modelled using the equation:

$$
\Delta \log N=N_{c}-N_{S}
$$

where $N_{c}$ and $N_{s}$ are cell numbers (log CFU/g) in the control and in each of the combinations of centroid, thus attaining two sets of data (i.e., $\Delta \log N 24$ and $\Delta \log N 48$ ), corresponding to the reduction of cell counts observed after 24 and $48 \mathrm{~h}$.

These data were used as inputs for a modelling approach through DoE theory (software Statistica for Windows) to build polynomial equations:

$$
\mathrm{y}=\sum_{i=1}^{3} \beta_{i} x_{i}+\sum_{i \leq}^{3} \sum_{j}^{3} \beta_{i j} x_{i} x_{j}+\sum_{i \leq}^{3} \sum_{j \leq}^{3} \sum_{k}^{3} \beta_{i j k} x_{i} x_{j} x_{k}+\varepsilon
$$

where $\beta_{i}, \beta_{i j}$, and $\beta_{i j k}$ are the coefficients of the individual $\left(x_{i}\right)$ and interactive effects $\left(x_{i} x_{j}-x_{i} x_{j} x_{k}\right)$ of the independent variables (vinegar, $\mathrm{NaCl}$, and citric acid); $\varepsilon$ is the standard error of the model.

Through polynomial equations, prediction profiles were built; in particular, two profiles were evaluated:

(a) Salt (vinegar and citric acid were fixed to the coded level 0 , that is, $40 \%$ and $0 \%$ );

(b) Citric acid (vinegar and salt at $40 \%$ and $0 \%$, respectively).

\subsection{Product Optimization}

\subsubsection{Sample Preparation}

Sea bream of the Adriatic Sea (Sparus aurata), supplied by the company Ittica di Dio (Molfetta, Italy) were used. The sea bream specimens were deheaded, gutted, washed, and filleted. The fillets were stripped of skin and immersed in a marinating saline solution consisting of $55 \%$ vinegar, $3 \% \mathrm{NaCl}$, and $0.75 \%$ citric acid for $48 \mathrm{~h}$ at $4{ }^{\circ} \mathrm{C}$. Then, the fillets were removed from the solution, inoculated with either L. plantarum 69 or B. animalis ( $8 \log \mathrm{CFU} / \mathrm{g}$ ) and packed in high-barrier nylon/polyethylene bags $(102 \mu \mathrm{m})$ by means of S100-Tecnovac equipment (Tecnovac, San Paolo D'Argon, Bergamo, Italy). Two types of conditioning brines were tested: (1) sample in sunflower oil (O); (2) sample in diluted brine (5.5\% vinegar, $0.3 \%$ salt, $0.075 \%$ citric acid) (S).

During storage at $4{ }^{\circ} \mathrm{C}$ for 21 days, samples were periodically analysed as described in the following. All analyses were conducted twice.

\subsubsection{Microbiological Analyses}

For microbiological analyses, the following media were used: plate count agar (PCA) incubated at $5{ }^{\circ} \mathrm{C}$ for 1 week and at $30{ }^{\circ} \mathrm{C}$ for $48 \mathrm{~h}$ under aerobic conditions for psychrotrophic bacteria and total bacteria count, respectively; Pseudomonas agar base (PAB), supplemented with Pseudomonas CFC supplement, incubated at $25^{\circ} \mathrm{C}$ for $48 \mathrm{~h}$ for Pseudomonadaceae; violet red bile glucose agar (VRBGA) incubated at $37^{\circ} \mathrm{C}$ for $24 \mathrm{~h}$ for Enterobacteriaceae; triple sugar iron agar (TSIA) incubated at $37^{\circ} \mathrm{C}$ for $24 \mathrm{~h}$ for specific spoilage microorganisms (SSOs). All the media and the supplements were from Oxoid (Milan, Italy). The media and the conditions used for probiotic bacteria were: MRS agar for L. plantarum 69 (MRSA) and NPNL-MRS agar (NPNL-MRSA) for Bifidobacterium animalis subsp. lactis 10140 , incubated at $37^{\circ} \mathrm{C}$ for $48 \mathrm{~h}$. The NPNL solution consisted of 
nalidixic acid (750 mg/L, Sigma-Aldrich, Milan), paromomycin sulphate (10 mg/L, SigmaAldrich), neomycin sulphate (5 mg/L, Sigma-Aldrich), and lithium chloride (150 mg/L, Sigma-Aldrich).

The measurement of $\mathrm{pH}$ was conducted in duplicate for each sampling on the fish homogenate with a Crison pH meter micro pH model 2001 (Crison, Barcelona, Spain).

\subsubsection{Sensory Analyses}

For sensory analyses, the samples were evaluated to assess the sensory scores in terms of colour, texture, odour, and overall acceptability through a quantitative descriptive analysis. The sensory evaluation panel consisted of 20 trained panellists aged between 25 and 50 years, who were students and researchers of the Department of Agriculture, Food, Natural Resources and Engineering (University of Foggia). Initial recruitment of panellists was performed using a questionnaire and pre-selecting members by means of a triangular test for salty and acidic tastes. Before the training, two pre-observation sessions were conducted where 2 persons observed the marinated fillets every day, recording the quality changes from the first day until it was spoiled. In this way, a primary grade system was established, in which 5 was the highest score, indicating the best quality of fish fillets on the first day, and 0 was the lowest score, indicating the spoiled fillets. The training session included 5 meetings during which panellists examined different fish samples to define the evaluation techniques and to become familiar with the organoleptic attributes of marinated fish products. In particular, in the first three sessions, panellists evaluated marinated fillets with a known storage time in order to choose appropriate parameters and modify the score range, making the system more efficient. Then, in sessions four and five, the marinated fillets were assigned three-digit random number blinding codes and evaluated for sensory characteristics. At the end of the session, the panellists were informed of the storage time. Thus, all parameters and the specific range of the score were fixed, completing the scheme used in the test sessions (Table 2).

Table 2. Sensory evaluation criteria.

\begin{tabular}{|c|c|c|}
\hline Quality Parameter & Description & Score \\
\hline \multirow{6}{*}{ Colour } & Glossy and bright surface & 5 \\
\hline & Slight glossy and bright surface & 4 \\
\hline & Slight glossy and dull surface & 3 \\
\hline & No glossy appearance, 1st discoloration & 2 \\
\hline & No glossy appearance, a little yellow surface & 1 \\
\hline & No glossy appearance, yellow surface & 0 \\
\hline \multirow{6}{*}{ Odour } & No fishiness and no earthy smell & 5 \\
\hline & Little fishiness, no off-odour & 4 \\
\hline & Little freshness, no off-odour & 3 \\
\hline & Little freshness, first off-odour & 2 \\
\hline & Distinct freshness and off-odour & 1 \\
\hline & Strong freshness and strong off-odour & 0 \\
\hline \multirow{6}{*}{ Texture } & Finger mark disappears immediately & 5 \\
\hline & Finger leaves mark less than $3 \mathrm{~s}$ & 4 \\
\hline & Finger leaves mark longer than $3 \mathrm{~s}$ & 3 \\
\hline & Muscle returns more than half way & 2 \\
\hline & Very soft, no elasticity & 1 \\
\hline & Highly soft, no elasticity, no connectivity & 0 \\
\hline
\end{tabular}


Table 2. Cont.

\begin{tabular}{llc}
\hline \multirow{2}{*}{ Quality Parameter } & \multicolumn{1}{c}{ Description } & Score \\
\hline \multirow{4}{*}{ Overall acceptance } & \multicolumn{1}{c}{ Fresh, totally acceptable } & 5 \\
\cline { 2 - 3 } & Little fresh, acceptable & 4 \\
\cline { 2 - 3 } & Little fresh, marginally acceptable & 2 \\
\cline { 2 - 3 } & Not fresh, unacceptable & 1 \\
\cline { 2 - 3 } & Not fresh, totally unacceptable & 0 \\
\cline { 2 - 3 } & Clearly spoiled & 2 \\
\hline
\end{tabular}

During the test sessions, marinated fish samples in plastic trays covered with a lid were presented individually to each panellist in random order; in addition to the marinated samples inoculated with probiotics and packed in sunflower oil or in the diluted brine, a master control sample (no probiotic addition) was also presented to panellists. Sensory evaluation was conducted in individual booths under controlled conditions of light (white light), temperature $\left(20 \pm 2{ }^{\circ} \mathrm{C}\right)$, and humidity $(70 \%$ to $85 \%)$. The score was assigned using a scale ranging from 0 to 5 , as detailed in Table 2 . Sample overall quality was an average of three sensory attributes (colour, odour, and texture).

Sensorial data were analysed through a MANOVA (multivariate analysis of variance); time, strain, and sample (SO and SS) were used as categorical predictors. Tukey's test was used as the post-hoc comparison test $(p<0.05)$.

In addition, spider profiles at selected time intervals were done; mean values were used as input data.

\section{Results}

\subsection{Brine Optimization}

This research intended to develop a probiotic marinated sea bream carpaccio for two reasons: 1 . sea bream is one of the most appreciated and consumed fish species at the national level; 2. marinated fish products are very popular with consumers, especially the traditional carpaccio products (cold marinated fish with salt, fruit juices, and acetic and citric acids). Furthermore, the use of mild technologies (generally used for their stabilization) could guarantee the survival of the probiotic microorganism during the processing and storage of the product [18].

During the marinating process, the preservative effect is achieved by an acidification of the product, obtained using solutions based in different amounts of vinegar or acetic acid and salt [22].

In this paper, the optimization of brine was addressed by the use of a mixture design, where each compound $(\mathrm{NaCl}$, vinegar $(\mathrm{V})$, and citric acid $(\mathrm{CA})$ ) is a component of a blend. The results after $24 \mathrm{~h}$ were analysed as viability loss (VL), whereas modelling was not performed after $48 \mathrm{~h}$ because the strains were always below the detection limit.

VL of L. plantarum 69 was influenced by the positive and linear terms of $\mathrm{NaCl}$, vinegar, and citric acid and by the interactions vinegar* $\mathrm{NaCl}$ and $\mathrm{NaCl}^{*}$ citric acid; that is, VL increased when $\mathrm{NaCl}$, vinegar, and citric acid increased. The polynomial equation reads as follows:

$V L=0.779[\mathrm{~V}]+6.818[\mathrm{NaCl}]+3.748[\mathrm{CA}]+13.480[\mathrm{~V}][\mathrm{NaCl}]+7.576[\mathrm{NaCl}][\mathrm{CA}]\left(\mathrm{R}^{2}, 0.982\right)$

The quantitative results are in the ternary plot (Figure 1). Although citric acid and vinegar were significant, the only compound able to exert a quantitative effect was $\mathrm{NaCl}$. In fact, viability loss was maximum (7 log CFU/g) for a code level of salt of 0.75-1.0 (that is, $9-12 \%)$. These results confirm the technological robustness of the strains recovered in laboratory media (i.e., inhibition in the presence of $10-12.5 \% \mathrm{NaCl}$ ) [17]. 


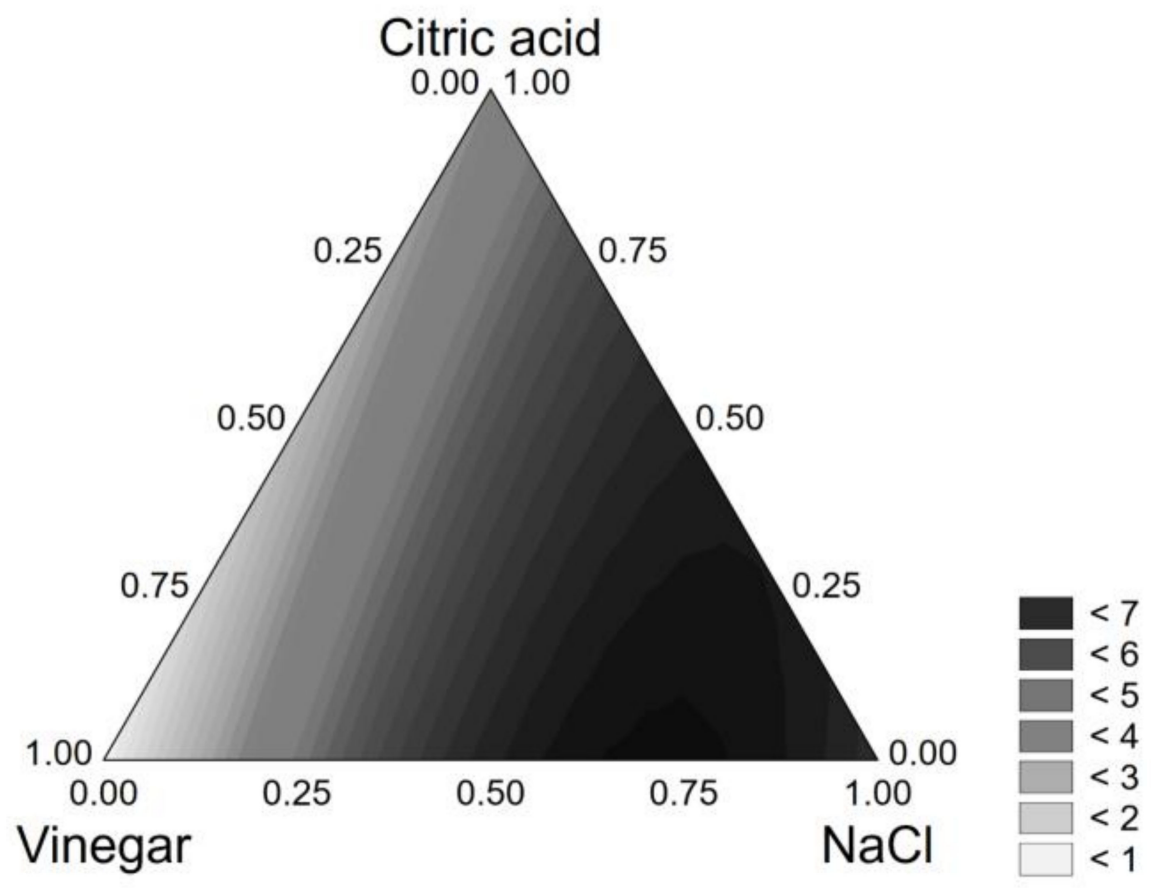

Figure 1. Ternary plot for the viability loss of L. plantarum 69 after $24 \mathrm{~h}$ in the model system.

The same modelling approach was used for the other strains. For L. plantarum 68, $\mathrm{NaCl}$ was significant as an individual term and in interaction with the vinegar; in this case, the least significant variable was vinegar. The polynomial equation reads as follows:

$V L=1.414[\mathrm{~V}]+2.998[\mathrm{NaCl}]+6.264[\mathrm{CA}]+9.706[\mathrm{~V}][\mathrm{NaCl}]+8.080[\mathrm{NaCl}][\mathrm{CA}]\left(\mathrm{R}^{2}, 0.922\right)$

For this strain, the highest viability loss $(6 \log \mathrm{CFU} / \mathrm{g})$ was found for the combination $\mathrm{NaCl}+$ citric acid, both at the coded level $0.5(6 \% \mathrm{NaCl}+0.75 \%$ citric acid) (Figure 2$)$.

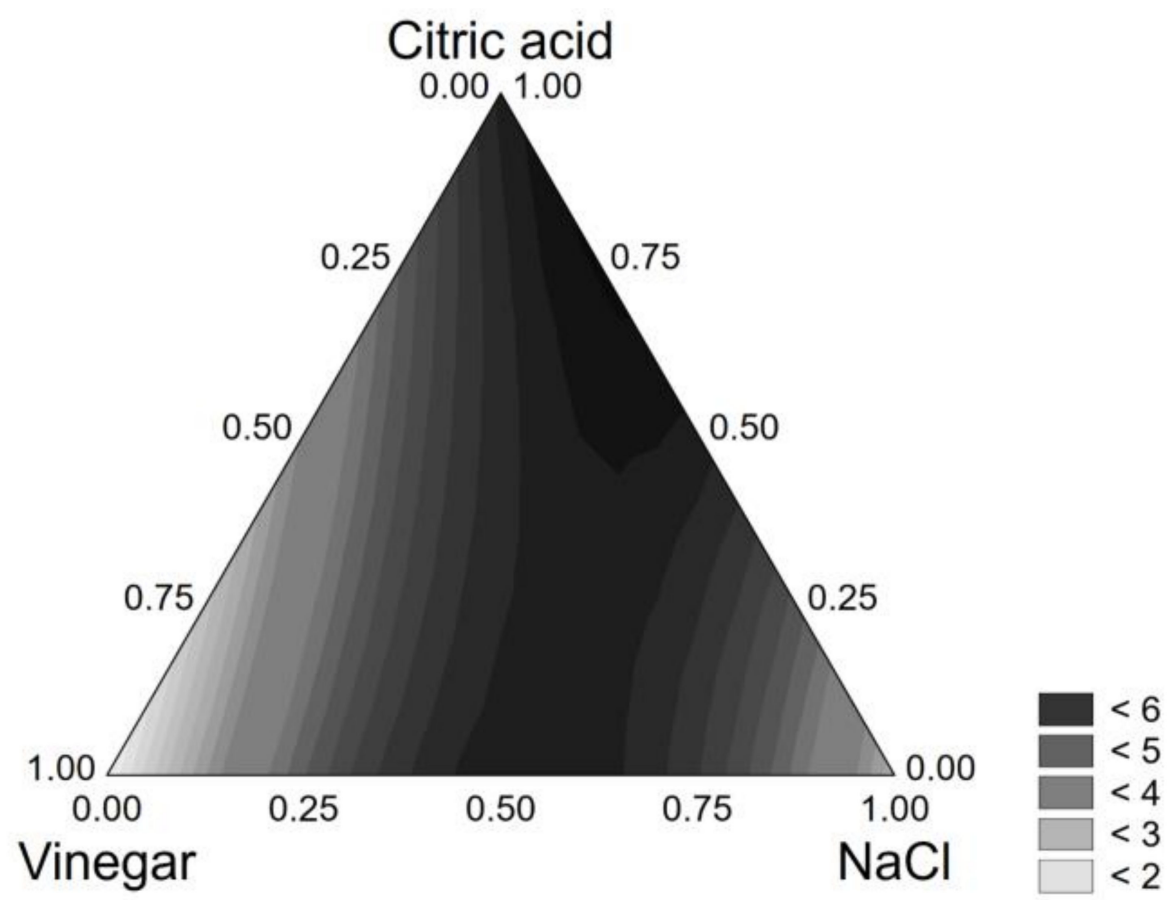

Figure 2. Ternary plot for the viability loss of L. plantarum 68 after $24 \mathrm{~h}$ in the model system. 
L. plantarum strain 11 was affected by $\mathrm{NaCl}$ and citric acid, both as individual and interactive terms, as well as by vinegar, although its statistical effect was low:

$$
V L=2.040[\mathrm{~V}]+6.202[\mathrm{NaCl}]+6.201[\mathrm{CA}]+7.696[\mathrm{~V}][\mathrm{NaCl}]+7.683[\mathrm{NaCl}][\mathrm{CA}]\left(\mathrm{R}^{2}, 0.988\right)
$$

This strain experienced a strong viability loss ( $6 \log \mathrm{CFU} / \mathrm{g})$ in many combinations of the design (among others $\mathrm{NaCl}+$ citric acid, $0.5+0.5$; citric acid + vinegar, $0.5+0.5 ; \mathrm{NaCl}+$ vinegar, $0.5+0.5 ; \mathrm{NaCl}+$ citric acid + vinegar, $0.33+0.33+0.33$ ) (Figure 3); therefore, it was regarded as unsuitable for product design.

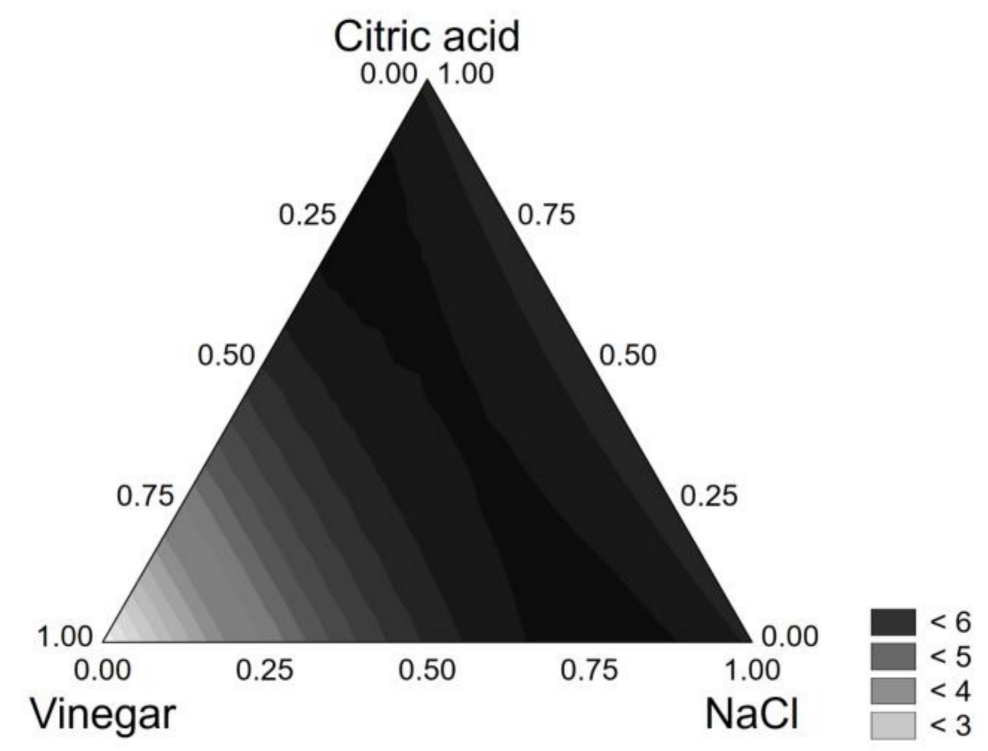

Figure 3. Ternary plot for the viability loss of L. plantarum 11 after $24 \mathrm{~h}$ in the model system.

Finally, B. animalis subsp. lactis was influenced by the $\mathrm{NaCl}$ and citric acid concentrations (as individual terms) and by the interactions vinegar*citric acid and citric acid ${ }^{*} \mathrm{NaCl}$, as shown in the following equation:

$$
V L=6.397[\mathrm{NaCl}]+4.502[\mathrm{CA}]+14.220[\mathrm{~V}][\mathrm{NaCl}]+5.653[\mathrm{NaCl}][\mathrm{CA}]\left(\mathrm{R}^{2}, 0.973\right)
$$

The highest $\mathrm{VL}$ was found for $\mathrm{NaCl}$ amounts of $9-12 \%$ (coded levels $0.75-1.0)$ (Figure 4).

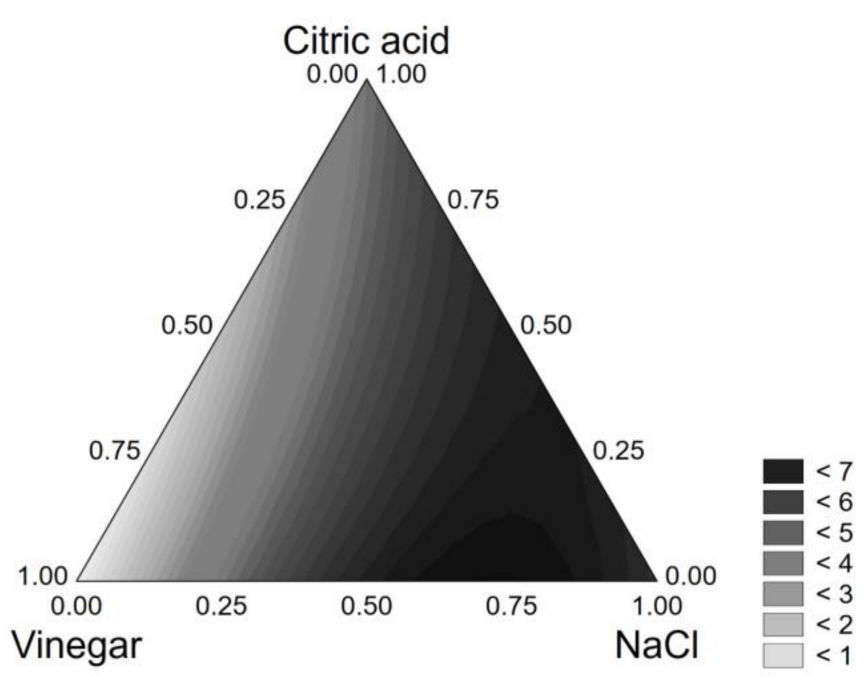

Figure 4. Ternary plot for the viability loss of B. animalis subsp. lactis DSM 10140 after $24 \mathrm{~h}$ in the model system. 
Ternary plots show the quantitative effect of the three factors of centroid; however, they do not allow an extrapolation of the individual effect of each independent variable. Thus, prediction profiles for salt and citric acid were built (Figure 5). Generally, viability loss increased when salt and citric acid increased (e.g., up to $7 \log \mathrm{CFU} / \mathrm{g}$ for B. animalis at $12 \% \mathrm{NaCl}$ or $6 \log \mathrm{CFU} / \mathrm{g}$ with $1.5 \%$ citric acid).
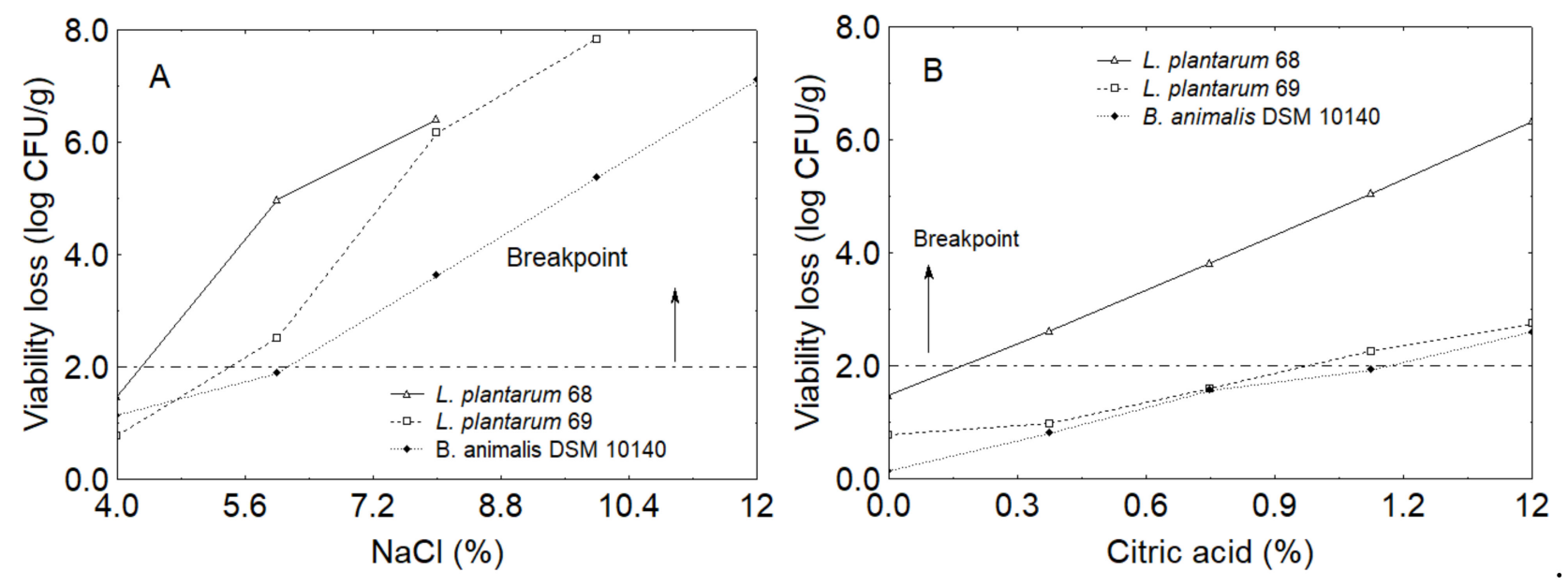

Figure 5. Prediction profiles: individual effect of $\mathrm{NaCl}(\mathbf{A})$ and citric acid (B) on the viability loss of B. animalis subsp. lactis DSM 10140, L. plantarum 68, and L. plantarum 69 in the model system (agar dishes).

For optimization, an arbitrary breakpoint was set (2 log CFU/g) and acceptable levels of salt and citric acid were recovered from prediction profiles, because it was not possible to find a saddle point (i.e., a combination of variables resulting in the lowest viability loss). Considering that the initial inoculum was $8 \log \mathrm{CFU} / \mathrm{g}$, a decrease of ca. $2 \log \mathrm{CFU} / \mathrm{g}$ could be considered acceptable, as the minimum level required for a probiotic strain in a food or probiotic drink is $6 \log$ CFU/g [22]. Table 3 shows the predicted coded values for these variables for each strain. L. plantarum 68 was cut off because it experienced a strong viability loss and the predicted coded values were too low for a marinating solution $(\mathrm{NaCl}$ at $0.04 \%$ and citric acid at $0.17 \%$ ). The critical values of $\mathrm{NaCl}$ and citric acid were set at $3 \%$ and $0.75 \%$, as shown by the prediction for the B. animalis. Vinegar was not a limiting factor and could also be set at maximum level (code level 1, equal to $70 \%$ ). However, the choice of the composition of brine should also be based on other elements, such as the effect on the organoleptic characteristics of products; therefore, the vinegar concentration was set to $55 \%$. Thus, the final composition chosen for the brine was $55 \%$ vinegar, $3 \% \mathrm{NaCl}, 0.75 \%$ citric acid.

Table 3. Brine optimization. Critical thresholds of $\mathrm{NaCl}$ and citric acid for the survival of L. plantarum 69 and B. animalis subsp. lactis DSM 10140 (viability loss < $2 \log$ CFU/g).

\begin{tabular}{ccccc}
\hline & \multicolumn{2}{c}{$\mathrm{NaCl}$} & \multicolumn{2}{c}{ Citric Acid } \\
\hline & Coded Values & Real Values & Coded Values & Real Values \\
\hline L. plantarum 69 & 0.23 & $2.76 \%$ & 0.63 & $0.95 \%$ \\
L. plantarum 68 & 0.04 & $0.50 \%$ & 0.11 & $0.17 \%$ \\
B. animalis 10140 & 0.25 & $3 \%$ & 0.50 & $0.75 \%$ \\
\hline
\end{tabular}

Only salt and citric acid had significant effects on the viability of the tested strains. Acids and salt are generally used to delay the action of bacteria and enzymes in fish. Ray and Bhunia [23] demonstrated that the addition of $0.3 \%$ acetic acid had a bactericidal effect, mainly against Gram-negative bacteria. Moreover, the interaction of salt with acids ensures not only specific product characteristics such as taste, appearance, or texture, but also environmental conditions that delay the growth of microorganisms that cause spoilage [24]. 
As reported by other authors $[17,25]$, the technological robustness and the resistance to salt and acids are strain-dependent; strains 11 and 68 showed a poor technological aptitude, thus, they were excluded from the second step of this research.

\subsection{Product Optimization}

Salt resistance and growth in acid conditions can be considered the necessary characteristics for a strain to be used in marinated fish products. Furthermore, important features that probiotic strains should fulfil are viability and the ability to create pleasant flavours, prolong shelf life, and have a useful impact on consumer health [26].

The aim of the second step was to assess these traits in real conditions by focusing on microbiological data, sensory scores, and $\mathrm{pH}$.

As a result of conditioning in the brine optimized in Section 3.1, the $\mathrm{pH}$ of the fish fillets decreased from 6.3 to 3.75-3.80, whereas specific spoilage microorganisms (SSOs), Pseudomonas spp., enterobacteria, and lactic acid bacteria were below the detection limit.

Table 4 reports the cell counts of probiotics on fish packed in sunflower oil $(\mathrm{O})$ or in the diluted brine (S) during 3 weeks of refrigerated storage. Neither L. plantarum 69 nor B. animalis experienced significant viability loss over time, while psychrotrophic bacteria, Pseudomonas spp., enterobacteria, and SSOs were below the detection limit (data not shown). The $\mathrm{pH}$ was at 3.7-3.8 for 21 days. As expected, microbial activity was inhibited due to the combined effect of saline and acid solutions; it is well known that the marinating process provides food safety with microbial inactivation [27].

Table 4. Cell counts (log CFU/g) of L. plantarum 69 and B. animalis subsp. lactis DSM 10140 in fish samples (mean \pm standard deviation). $\mathrm{O}$, packaged in sunflower oil; $\mathrm{S}$, packaged in brine.

\begin{tabular}{ccccc}
\hline \multirow{2}{*}{ Time (Days) } & \multicolumn{2}{c}{ L. plantarum 69 } & \multicolumn{2}{c}{ B. animalis $\mathbf{1 0 1 4 0}$} \\
\cline { 2 - 5 } & $\mathbf{O}$ & $\mathbf{S}$ & $\mathbf{O}$ & S \\
\hline 0 & $7.85 \pm 0.20 \mathrm{a}$ & $7.78 \pm 0.16 \mathrm{a}$ & $7.75 \pm 0.15 \mathrm{a}$ & $7.80 \pm 0.19 \mathrm{a}$ \\
2 & $7.18 \pm 0.08 \mathrm{~d}$ & $7.20 \pm 0.20 \mathrm{~d}$ & $7.75 \pm 0.24 \mathrm{a}$ & $7.68 \pm 0.12 \mathrm{a}$ \\
7 & $7.65 \pm 0.18 \mathrm{a}$ & $7.72 \pm 0.30 \mathrm{a}$ & $7.77 \pm 0.21 \mathrm{a}$ & $7.34 \pm 0.14 \mathrm{c}$ \\
10 & $7.33 \pm 0.15 \mathrm{c}$ & $7.50 \pm 0.25 \mathrm{~b}$ & $7.43 \pm 0.19 \mathrm{~b}$ & $7.50 \pm 0.20 \mathrm{~b}$ \\
14 & $7.30 \pm 0.22 \mathrm{c}$ & $7.37 \pm 0.19 \mathrm{c}$ & $7.29 \pm 0.08 \mathrm{c}, \mathrm{d}$ & $7.30 \pm 0.18 \mathrm{c}$ \\
21 & $7.20 \pm 0.10 \mathrm{~d}$ & $7.35 \pm 0.15 \mathrm{c}$ & $7.35 \pm 0.20 \mathrm{c}$ & $7.45 \pm 0.25 \mathrm{~b}, \mathrm{c}$ \\
\hline
\end{tabular}

Different letters indicate significant differences (one-way ANOVA and Tukey's test, $p<0.05$ ).

Several studies reported that fish could be considered a suitable matrix supporting the viability of LAB, mainly probiotic strains [19,28]. Giribaldi et al. [19] reported that the probiotic strain L. paracasei IMPC 2.1, inoculated in marinated ready-to-eat swordfish fillets, was not only able to survive up to 90 days of refrigerated storage, but also to improve the fatty acid profile and oxidative stability of the studied products.

In this study, the cell loads of L. plantarum 69 and B. animalis 10140 never reached the critical value during the 21 days of the experiment. Thus, a preliminary evaluation of the shelf life was determined based on the sensory scores. Generally, time was the most significant factor for colour, odour, texture, and overall acceptability; the kind of sample (packaged in oil or in diluted brine) also played a role. Figure 6 shows the decomposition of the statistical hypothesis for the overall quality. As expected, sensory scores decreased over time (Figure 6A; $p<0.001$ ), with a higher decrease in diluted brine (Figure 6B; $p<0.001$ ) and with L. plantarum 69 (Figure 6C; p, 0.004), although the critical breakpoint for the sensory scores was never attained. 

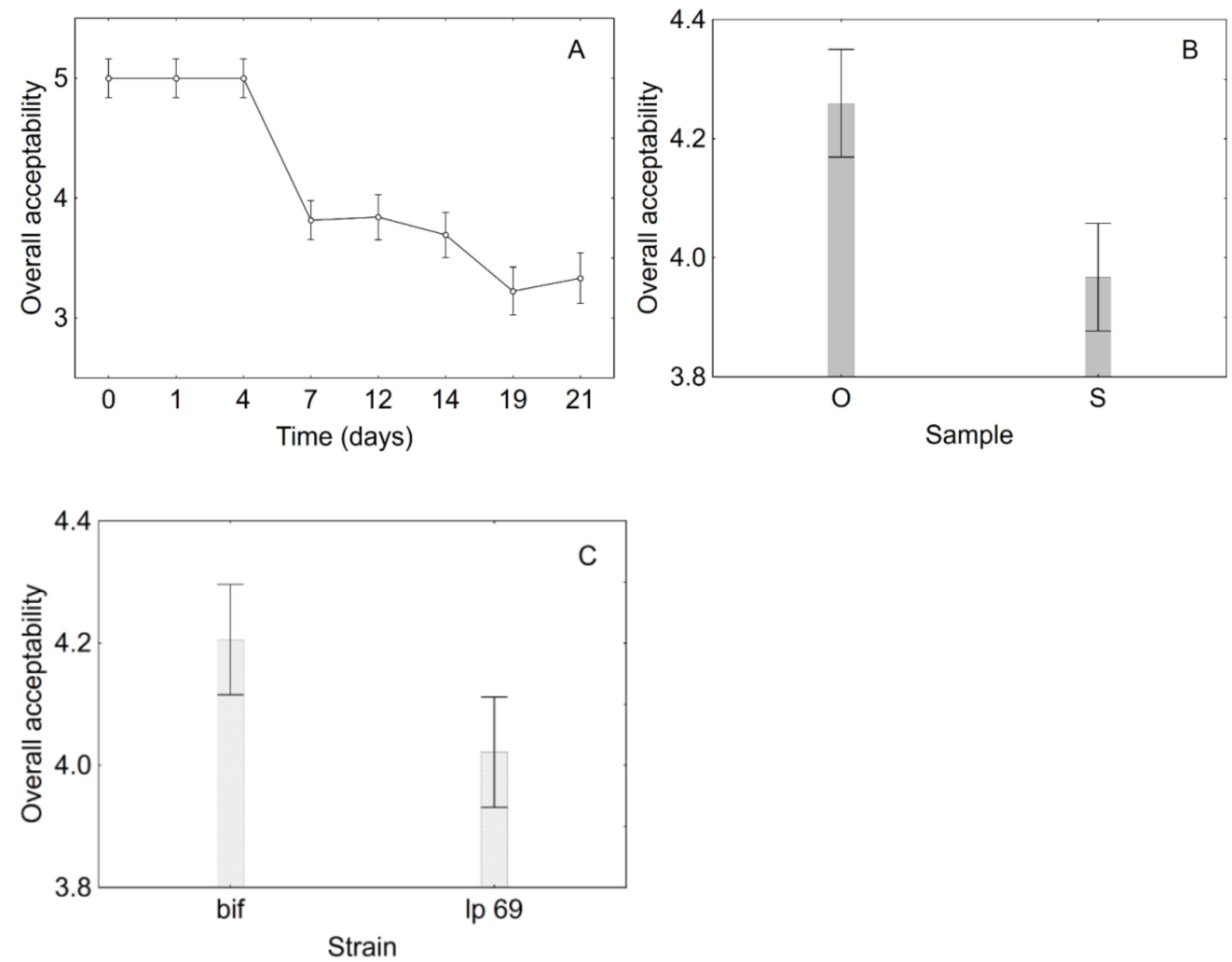

Figure 6. Decomposition of the statistical hypothesis for the effects of time (A), sample (B), and strain (C) on the overall acceptability. O, products in sunflower oil; S, products in diluted brine. Bif, B. animalis subsp. lactis DSM 10140; lp 69, L. plantarum 69.

The time*sample interaction was important for the odour, because the samples in oil retained higher scores up to 4 days (Figure $7 ; p, 0.001$ ).

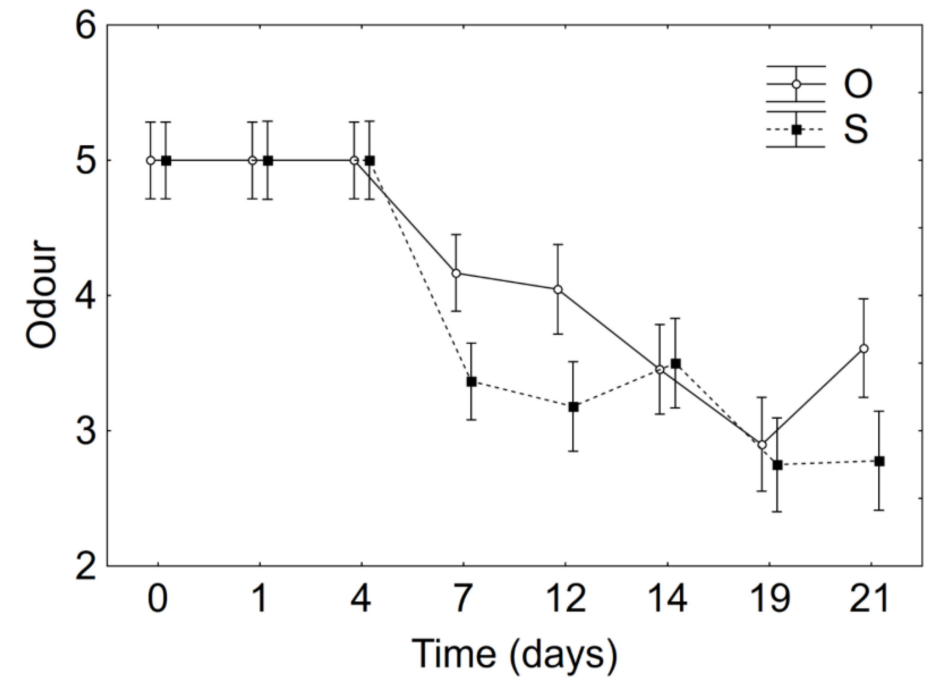

Figure 7. Decomposition of the statistical hypothesis for the interaction sample*time on odour. O, products in sunflower oil; S, products in diluted brine.

As a last step, spider profiles of samples were made at days 12 and 21 (Figure 8). These pictures offer an overview of the general sensory profile and show the worsening of the sample in the diluted brine inoculated with L. plantarum 69, as also suggested by MANOVA. 

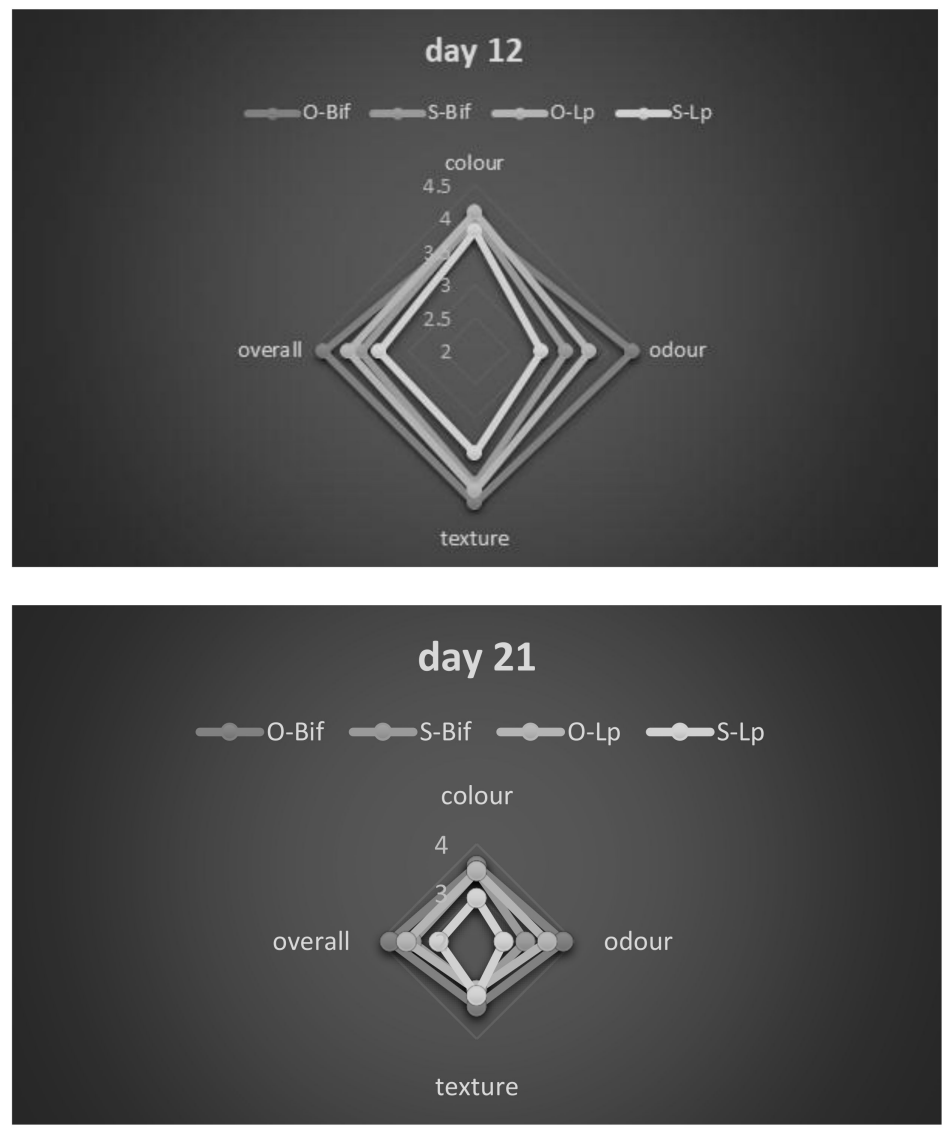

Figure 8. Spider graphs at days 12 and 21. O, products in sunflower oil; S, products in diluted brine; Lp, product inoculated with L. plantarum 69; Bif, product inoculated with B. animalis.

Some authors reported that marinated fish has a limited shelf life in refrigerated storage (e.g., 1 month), and is influenced by the quality of the raw material, the storage temperature, the levels of preservatives (salt, quantity of vinegar/acetic acid), and the possible use of other additives [24,29-34]. The shelf life of the product proposed in this research is similar, at least for the viability of the two strains. However, sensory scores were the limiting factor, and the product retained the best performance for 4 days.

In conclusion, this paper proposes a product combining functional strains and mild technologies on sea bream fillets as a prodromal step to design a new carrier for functional microorganisms. The bacteria retained a high viability throughout storage (21 days); however, the sensory scores were at their highest level for 4 days.

For the formulation, sensory assessment suggested a preference for a conditioning solution with oil, rather than with a diluted brine; in addition, a slightly higher preference was found for B. animalis subsp. lactis.

Author Contributions: Conceptualization, M.R.C. and B.S.; methodology, A.B.; investigation, A.R., B.S., and D.C.; data curation, B.S. and A.B.; writing-original draft preparation, A.R. and A.B.; writing - review and editing, all authors; funding acquisition, M.R.C. and M.S. All authors have read and agreed to the published version of the manuscript.

Funding: This research was funded by the Italian Ministry of the University and Research (M.I.U.R.) by the research project PON01_01962: “Tecnologie per la valorizzazione e l'estensione di shelf life di trasformati ittici a elevata valenza salutistica".

Conflicts of Interest: The authors declare no conflict of interest. 


\section{References}

1. Dinkçi, N.; Akdeniz, V.; Akalin, A.S. Survival of probiotics in functional foods during shelf life. In Food Quality and Shelf Life; Galanakis, C.M., Ed.; Academic Press: Philadelphia, PA, USA, 2019; pp. 201-233.

2. Gareau, M.G.; Sherman, P.M.; Walker, W.A. Probiotics and the gut microbiota in intestinal health and disease. Nat. Rev. Gastro. Hepat. 2010, 7, 503-514. [CrossRef]

3. Gupta, S.; Abu-Ghannam, N. Probiotic fermentation of plant based products: Possibilities and opportunities. Crit. Rev. Food Sci. 2012, 52, 183-199. [CrossRef]

4. Peres, C.M.; Peres, C.; Hernández-Mendoza, A.; Malcata, F.X. Review on fermented plant materials as carriers and sources of potentially probiotic LAB_With an emphasis on table olives. Trends Food Sci. Tech. 2012, 26, 31-42. [CrossRef]

5. Vijaya Kumar, B.; Sreedharamurthy, M.; Reddy, O.V.S. Physicochemical analysis of fresh and probioticated fruit juices with Lactobacillus casei. Int. J. App. Sci. Biotech. 2013, 1, 127-131. [CrossRef]

6. Vijayendra, S.V.N.; Halami, P.M. Fermented vegetables-health benefits. In Fermented Vegetables; Tamang, J.P., Ed.; CRC Taylor \& Francis Publisher: Boca Raton, FL, USA, 2015; pp. 327-344.

7. Sidira, M.; Karapetsas, A.; Galanis, A.; Kanellaki, M.; Kourkoutas, Y. Effective survival of immobilized Lactobacillus casei during ripening and heat treatment of probiotic dry-fermented sausages and investigation of the microbial dynamics. Meat Sci. 2014, 96, 948-955. [CrossRef]

8. Rivera-Espinoza, Y.; Gallardo-Navarro, Y. Non-dairy prebiotic products. Food Microbiol. 2010, 27, 1-11. [CrossRef] [PubMed]

9. Tacon, A.G.J.; Metian, M. Food matters: Fish, income, and food supply-A comparative analysis. Rev. Fish. Sci. Aquac. 2017, 26, 15-28. [CrossRef]

10. Zang, J.; Xu, Y.; Xia, W.; Jiang, Q.; Yang, F.; Wang, B. Phospholipid molecular species composition of Chinese traditional low-salt fermented fish inoculated with different starter cultures. Food Res. Int. 2018, 111, 87-96. [CrossRef]

11. Vilavert, L.; Borrell, F.; Nadal, M.; Jacobs, S.; Minnens, F.; Verbeke, W.; Marques, A.; Domingo, J.L. Health risk/benefit information for consumers of fish and shellfish: Fish choice, a new online tool. Food Chem. Toxicol. 2017, 104, 79-84. [CrossRef] [PubMed]

12. Nestel, P.; Clifton, P.; Colquhoun, D.; Noakes, M.; Mori, T.A.; Sullivan, D. Indications for Omega-3 long chain polyunsaturated fatty acid in the prevention and treatment of cardiovascular disease. Heart Lung Circ. 2015, 24, 769-779. [CrossRef] [PubMed]

13. Baik, I.; Abbott, R.D.; Curb, J.D.; Shin, C. Intake of fish and n-3 fatty acids and future risk of metabolic syndrome. J. Am. Diet. Assoc. 2010, 110, 1018-1026. [CrossRef] [PubMed]

14. Siscovick, D.S.; Barringer, T.A.; Fretts, A.M.; Wu, J.H.Y.; Lichtenstein, A.H.; Costello, R.B.; Kris-Etherton, P.M.; Jacobson, T.A.; Engler, M.B.; Alger, H.M.; et al. American heart association nutrition committee of the council on lifestyle and cardiometabolic health, council on epidemiology and prevention, council on cardiovascular disease in the young, council on cardiovascular and stroke nursing, \& council on clinical cardiology. Omega-3 polyunsaturated fatty acid (fish oil) supplementation and the prevention of clinical cardiovascular disease: A science advisory from the American Heart Association. Circulation 2017, 135, 867-884.

15. Tacon, A.G.J.; Metian, M. Fish matters: Importance of aquatic foods in human nutrition and global food supply. Rev. Fish. Sci. 2013, 21, 22-38. [CrossRef]

16. Semjonovs, P.; Auzina, L.; Upite, D.; Grube, M.; Shvirksts, K.; Linde, R.; Denina, I.; Bormanis, A.; Upitis, A.; Ruklisha, M.; et al. Application of Bifidobacterium animalis subsp. lactis as starter culture for fermentation of Baltic herring (Clupea harengus membras) mince. Am. J. Food Tech. 2015, 10, 184-194.

17. Speranza, B.; Racioppo, A.; Beneduce, L.; Bevilacqua, A.; Sinigaglia, M.; Corbo, M.R. Autochthonous lactic acid bacteria with probiotic aptitudes as starter cultures for fish-based products. Food Microbiol. 2017, 65, 244-253. [CrossRef]

18. Speranza, B.; Bevilacqua, A.; Sinigaglia, M.; Corbo, M.R. Shelf life definition for Italian anchovies inoculated with Lactobacillus plantarum and Bifidobacterium animalis subsp. lactis. Innov. Food Sci. Emerg. Tech. 2012, 16, 171-180. [CrossRef]

19. Giribaldi, M.; Gai, F.; Peiretti, P.G.; Ortoffi, M.F.; Lavermicocca, P.; Lonigro, S.L.; Valerio, F.; Cavallarin, L. Quality of ready-to-eat swordfish fillets inoculated with Lactobacillus paracasei IMPC 2.1. J. Sci. Food Agr. 2019, 99, 199-209. [CrossRef]

20. Zheng, J.; Wittouck, S.; Salvetti, E.; Franz, C.M.A.P.; Harris, H.M.B.; Mattarelli, P.; O’Toole, P.W.; Pot, B.; Vandamme, P.; Walter, J.; et al. A taxonomic note on the genus Lactobacillus: Description of 23 novel genera, emended description of the genus Lactobacillus Beijerinck 1901, and union of Lactobacillaceae and Leuconostocaceae. Int. J. Syst. Evolut. Microbiol. 2020, 70, 2782-2858. [CrossRef]

21. Speranza, B.; Racioppo, A.; Bevilacqua, A.; Beneduce, L.; Sinigaglia, M.; Corbo, M.R. Selection of autochthonous strains as starter cultures for fermented fish products. J. Food Sci. 2015, 80, M151-M160. [CrossRef]

22. FAO. Guidelines for the Evaluation of Probiotics in Food: Report of a Joint FAO; FAO: Rome, Italy, 2013.

23. Ray, B.; Bhunia, A. Fundamental Food Microbiology, 4th ed.; CRC Press: Boca Raton, FL, USA, 2008; Chapter 16.

24. Šimat, V.; Mićunović, A.; Bogdanović, T.; Listeš, I.; Generalić Mekinić, I.; Hamed, I.; Skroza, D. The impact of lemon juice on the marination of anchovy (Engraulis Encrasicolus): Chemical, microbiological and sensory changes. Ital. J. Food Sci. 2019, 31, 604-617.

25. Sanchez, B.; Champomier-Verges, M.C.; Collado, M.C.; Anglade, P.; Baraige, F.; Sanz, Y.; de Los Reys-Gavillán, C.G.; Margolles, A.; Zagorec, M. Low-pH adaptation and the acid tolerance response of Bifidobacterium longum biotype longum. Appl. Environ. Microb. 2007, 73, 6450-6459. [CrossRef] [PubMed]

26. Neffe-Skocińska, K.; Rzepkowska, A.; Szydłowska, A.; Kołożyn-Krajewska, D. Trends and possibilities of the use of probiotics in food production. In Handbook of Food Bioengineering, Alternative and Replacement Foods; Holban, A.M., Grumezescu, A.M., Eds.; Academic Press: Cambridge, MA, USA, 2018; pp. 65-94. 
27. Gokoglu, N.; Ucak, I. Effect of freshness grade of anchovy (Engraulis encrasicolus) on the quality of marinated product stored at $4{ }^{\circ} \mathrm{C}$. Aquat. Sci. 2020, 2, 54-59. [CrossRef]

28. Valerio, F.; Lonigro, S.L.; Giribaldi, M.; Di Biase, M.; De Bellis, P.; Cavallarin, L.; Lavermicocca, P. Probiotic Lactobacillus paracasei IMPC 2.1 strain delivered by ready-to-eat swordfish fillets colonizes the human gut after alternate-day supplementation. J. Funct. Foods 2015, 17, 468-475. [CrossRef]

29. Cadun, A.; Cackli, S.; Kisla, D. A study of marination of deepwater pink shrimp (Parapenaeus longirostris, Lucas, 1846) and its shelf life. Food Chem. 2005, 90, 53-59. [CrossRef]

30. Esaiassen, M.; Nilsen, H.; Joensen, S.; Skjerdal, T.; Carlehog, M.; Eilertsen, G.; Gundersen, B.; Elvevoll, E. Effects of catching method on quality changes during storage of cod (Gadhus morhua). Lebensm. Wiss. Technol. 2004, 37, 643-648. [CrossRef]

31. Gokoglu, N.; Cengiz, E.; Yerlikaya, P. Determination of the shelf life of marinated sardine (Sardina pilchardus) stored at $4{ }^{\circ} \mathrm{C}$. Food Control 2004, 15, 1-4. [CrossRef]

32. Gokoglu, N.; Topuz, O.K.; Yerlikaya, P. Effects of pomegranate sauce on quality of marinated anchovy during refrigerated storage. LWT Food Sci. Technol. 2009, 42, 113-118. [CrossRef]

33. Kilinc, B.; Cakli, S. Determination of the shelf life of sardine (Sardina pilchardus) marinades in tomato sauce stored at $4{ }^{\circ} \mathrm{C}$. Food Control 2005, 16, 639-644. [CrossRef]

34. Sallam, K.I.; Ahmed, A.M.; Elgazzar, M.M.; Eldaly, E.A. Chemical quality and sensory attributes of marinated Pacific saury (Cololabis saira) during vacuum-packaged storage at $4{ }^{\circ} \mathrm{C}$. Food Chem. 2007, 102, 1061-1070. [CrossRef] 